\title{
Medical Chart Review
}

National Cancer Institute

\section{Source}

National Cancer Institute. Medical Chart Review. NCI Thesaurus. Code C64254.

A procedure of review of the quality of a chart's documentation and coding by a certified professional medical auditor. 